\title{
Big Data Analytics and Business Failures in Data-Rich Environments: An Organizing \\ Framework
}

\section{Joseph Amankwah-Amoah'; Samuel Adomako}

\author{
Corresponding author: J.Amankwah-Amoah@kent.ac.uk
}

Dr Joseph Amankwah-Amoah is an Associate Professor (Reader) of international business at University of Kent. His research interests include strategic renewal, global business strategy, business failure, and lateral hiring in emerging economies. He has published in many journals of international repute including Technological Forecasting and Social Change, Industrial and Corporate Change, International Journal of Human Resource Management, Business History, Group and Organization Management, International Journal of Production Economics, and Journal of Business Research. He currently serves as an Associate Editor for Critical Perspectives on International Business and co-editor of the Cogent Business \& Management.

Dr Samuel Adomako is a lecturer in strategy at the School of Management, University of Bradford. His research examines the nexus of entrepreneurship, innovation, and creativity and decision making process of small business internationalization. His research has appeared in leading journals including International Small Business Journal, Business Strategy and the Environment, Journal of Business Research, Journal of International Management and many others. He received his PhD from the University of Warwick, United Kingdom.

Note: This paper has been accepted for publication in Computers in Industry (CABS 3*)

\footnotetext{
${ }^{1}$ Kent Business School, University of Kent, UK. Email: J.Amankwah-Amoah@kent.ac.uk

${ }^{2}$ School of Management, University of Bradford, Bradford, United Kingdom Email: S.Adomako@bradford.ac.uk
} 


\title{
Big Data Analytics and Business Failures in Data-Rich Environments: An Organizing Framework
}

\begin{abstract}
In view of the burgeoning scholarly works on big data and big data analytical capabilities, there remains limited research on how different access to big data and different big data analytic capabilities possessed by firms can generate diverse conditions leading to business failure. To fill this gap in the existing literature, an integrated framework was developed that entailed two approaches to big data as an asset (i.e. threshold resource and distinctive resource) and two types of competences in big data analytics (i.e. threshold competence and distinctive/core competence). The analysis provides insights into how ordinary big data analytic capability and mere possession of big data are more likely to create conditions for business failure. The study extends the existing streams of research by shedding light on decisions and processes in facilitating or hampering firms' ability to harness big data to mitigate the cause of business failures. The analysis led to the categorization of a number of fruitful avenues for research on data-driven approaches to business failure.
\end{abstract}

Keywords: big data analytics; technology; innovation management; big data; business failure. 


\section{Introduction}

With more than a decade into the 21 st century, one area of research that has attracted increased scholarly attention is business failure and learning from failure (Baumard \& Starbuck, 2005; Byrne \& Shepherd, 2015). Arguably, this period represents the "Golden Age" of business failure research with novel streams of works flourishing on issues such as stigmatisation of business failure (Wiesenfeld, Wurthmann \& Hambrick, 2008), successive entrepreneurial engagement after failure (Hessels, Grilo, Thurik \& van der Zwan, 2011) and human capital depletion from failing firms (Amankwah-Amoah, 2018; Jiang, Cannella, Xia \& Semadeni, 2017). Although companies are increasingly subjected to what Schumpeter (1942) referred to as forces of "creative destruction" which accelerated the failure rate for firms, relatively few studies have delved into the intricate processes, decision points and stages that precipitate business failures.

In parallel, another flourishing body of research is on big data and big data analytics (BDA) (Akter, Wamba, Barrett, \& Biswas, 2018; Gupta \& George, 2016; Horita, de Albuquerque, Marchezini \& Mendiondo, 2017; Sheng et al., 2017; Salehan, \& Kim, 2016; Wamba, Akter, \& De Bourmont, 2018; Wamba et al., 2017). After more than a decade of uninterrupted generation of new data, many market- and efficiency-seeking firms have earmarked considerable financial and human capital towards accumulating and harnessing big data. In the information age, the importance of big-data-driven decision making in determining organisational success or even failure has gained prominence (Janssen et al., 2017). Big data research has also focused on issues such as how firms can utilise such data to improve firm performance and develop competitive advantage (Akter et al., 2016; Zeng \& Glaister, 2018). Interestingly, some recent contributions to this stream of research have focused on how firms utilise big data in formulating strategies (Janssen, van der Voort \& Wahyudi, 2017). 
In spite of the potential linkages between these two growing streams of research, scholars have largely circumvented this area. Accordingly, we lack a systematic understanding of how big data can be harnessed to improve our understanding of business failure and in mitigating business failures. Although firms may possess different big data analytic capability and access to big data, much of the existing literature has failed to account for these differences and lump all firms into one broad category. Furthermore, we also lack solid understanding of how these differences can lead to different types of business failure. The dearth of scholarly works on this is surprising given that learning from business failure and big data utilisation are ultimately connected to decisions within many modern organisations.

To fill this lacuna in our understanding, the main purpose of this paper is to examine how different access to big data and different big data analytic capabilities possessed by firms can generate different conditions leading to business failure.

The paper offers several contributions to big data, business failure and business strategy literature. First, some research has highlighted the importance of big data in determining organisational success or failure, without delving into the intricate processes in how big data can be harnessed at different stages in mitigating business failure. Thus, the paper augments the burgeoning streams of research on business failure (Gerstrøm \& Isabella, 2015) and big data (Akter et al., 2016; Caesarius and Hohenthal, 2018; Leeflang, Verhoef, Dahlström \& Freundt, 2014; Nikolopoulos and Petropoulos, 2018) by developing a model of how big data can be harnessed at different stages in organisations towards mitigating business failure. The paper also elucidates the more intricate processes of how BDA can be leveraged to mitigate business failures. In addition, although some of the foundations towards better understanding of business failure have been laid by past studies (e.g. D'Aveni, 1989a, 1989b), the evolution of big data is recent and remains largely unaccounted for in the literature. Drawing on the literature on BDA (Wamba et al., 2017; 
Wamba, Gunasekaran, Dubey, \& Ngai, 2018) and business failure (Mellahi \& Wilkinson, 2004), a framework is developed to demonstrate how big data can be harnessed to help minimise the likelihood of business failure. The framework highlights different sources of organisational decision errors, mismanagement and blunders, and how big data can be utilised at different stages to improve organisational survival.

Furthermore, given the recent calls to examine the different facets of big data and how it can be harnessed to help improve understanding of firm performance (Sheng et al., 2017), it is unfortunate that limited studies have attempted to explore the more intricate processes of how BDA can be leveraged to mitigate business failures. Thus, the study contributes to the literature by classifying how different levels of big data and BDA capability can influence and inform organisation decisions. Thus, we provide a more systematic understanding of factors at firm level that create conditions for business failure to occur. By identifying and classifying the processes and decision points inherent in business failure, the paper offers a fundamental step in understanding how and why some organisations experience decline but generate turnaround whilst others experienced decline and collapsed spectacularly. Hence, we demonstrate human capital is critical in explaining underperforming failures and those unable to generate turnaround.

This paper is organised as follows. In the section that follows, we outline the foundations of our conceptual framework by presenting a brief review of the literature on business failure and BDA. This is then followed by an examination of the features of the framework. After this, we outline the challenges in harnessing big data to help improve organisational survivability. We conclude by setting out the wider theoretical and practical implications of the analysis. 


\section{Big data analytics and business failure: definitions and scope}

\subsection{Business failure}

Generally speaking, business failure refers to "the actual demise of the organization when an entire company goes out of business ... the organization completely ceases to exist" (Marks \& Vansteenkiste, 2008, p. 810). This may stem from an accumulation of decision and strategic errors (Amankwah-Amoah, 2016; Nutt, 2002). We conceptualised the causal dimensions to include the locus of causality and controllability of the cause (see Curren, Folkes \& Steckel, 1992). Regarding the locus of causality, prior research has essentially viewed business failure through two perspectives: endogenous and exogenous views (Amankwah-Amoah, Boso and Antwi-Agyei, 2016; Mellahi \& Wilkinson, 2004). The endogenous perspective explores the locus of causality by examining the actions and inactions of managers, manager's ability and leadership style as causes of business failure. Some scholars have attributed business failures to "poor or incompetent management" (Ronstadt, 1986). A line of research has also paid attention to the lack of highly skilled employees and firm strategies as components of the internal factors (AmankwahAmoah, 2016; Amankwah-Amoah, Antwi-Agyei and Zhang, 2018). These deficiencies often lead to a lack of creativity and limited or non-existing business intelligence units, thereby creating conditions for business failure.

Following these works, business failure also may stem from intra-organisational conflicts which divert resources and attention towards resolving conflicts, thereby creating potential for mistakes to flourish. The exogenous perspective rests on the assumption that failure stems from uncontrollable external factors such as technology change, rival firms' actions, competition, luck and state of the economy (Amankwah-Amoah, 2016). Past studies have demonstrated that new technology can render many traditional sources of competitive advantage such as location and land obsolete (see Bartels, Ermel, Sandborn \& Pecht, 2012). This issue is important given that 
technology and new technology introduction might exert different pressures on firms, leading to business closure. Scholars have demonstrated that intense industry competition through deregulation and liberalisation can drive out less-efficient firms (Knott \& Posen, 2005; Silverman, Nickerson \& Freeman, 1997). The liberalisation and deregulation of the 1980s and 1990 in most parts of the world has ushered in a more intensely competitive environment (Doganis, 2006).

In recent years, global consolidation of industries has unleashed new sources of competition, exerting pressure on firms and leading to their collapse. The intense competition in a host of industries now means there is less room for strategic error and blunders leading to misallocation of limited resources. As competition intensifies across an array of industries, it has become a strategic imperative for firms seeking competitive advantage to forge closer relationships with key stakeholders and well as stay in tune with customers' demands and changing customer behaviours (Xiong \& Bharadwaj, 2013).

\subsection{Big data analytics}

Historically, access to customers' data and companies' records was limited by the extremely high storage cost and space (Perrons \& Jensen, 2015). The accumulation of data that could equip firms for market competition tended to be a protracted and costly process. Since the start of this century, the sharp decline in data storage costs coupled with technological advancements have ushered in a new era in which firms' ability to collect voluminous data and store them have been enhanced enormously (Perrons \& Jensen, 2015). Big data broadly refers to "the amount of data just beyond technology's capability to store, manage and process efficiently" (Kaisler, Armour, Espinosa \& Money, 2013, pp. 995-1004; Cobb, Benjamin, Huang, \& Kuo, 2018) and exhibits features including velocity, volume, and variety (Fan, Lau, \& Zhao, 2015). Big data includes large volumes of data generated and captured from social media platforms such as WeChat, LinkedIn, Facebook and Twitter. The data can also be obtained from internal or external sources 
and can be structured or/and unstructured. BDA broadly refers to the "holistic approach to managing, processing and analyzing the $5 \mathrm{~V}$ data-related dimensions (i.e. volume, variety, velocity, veracity and value) to create actionable ideas for delivering sustained value, measuring performance and establishing competitive advantages" (Wamba et al., 2017, p. 356; Wamba et al., 2015). This refers to a firm's capacity to assemble and exploit BDA to improve organisational performance and ultimately deliver superior competitive advantage.

As Bharadwaj and Noble (2015, p. 476) pointed out, firms need to be skilful in transforming data to information to generate insights in solving organisational problems. Some of the advanced BDA techniques include data mining, predictive analytics, machine learning and text analytics. In more recent work, it has been postulated that the mere possession of data that is high in variety and velocity does not in itself yield sustainable competitive advantage, rather it is the ability to assemble these structured and unstructured data, analyse them and utilise the insights to inform organisations' decisions that produce such advantage (see Sheng et al., 2017). In other words, the notion that big data is an asset and a "single silver-bullet" solution in today's highly competitive global environment is false (Perrons \& Jensen, 2015) given that data alone are unlikely to yield competitive advantage (Wamba et al., 2017). Relying purely on assembling of data without transitioning into analytics to inform organisational decisions is more likely to lead to underutilisation of "assets" and consequently business failure.

One of the key features of BDA is that it can equip firms with opportunities to assemble, analyse and utilise big data to develop an array of strategic options for the firm (Wamba et al., 2017, 2018). There is evidence that some firms have utilised a loyalty-card programme to track and better predict customers' behaviour (Wamba et al., 2017). Accordingly, big data analytics capability (BDAC) is conceptualised to refer broadly to firms' ability to take advantage of data analytics to develop capabilities which equips it to develop costly-to-imitate capabilities in the big 
data environment, leading to sustainable competitive advantage (Dubey, Gunasekaran and Childe, 2018; Wamba et al., 2017; see also Barney and Clark, 2007).

The crux of the matter is that by developing BDAC, firms are better able to take full advantage of other functional expertise including marketing skills and product delivery. The notion of harnessing big data to gain competitive advantage is partly anchored in the knowledge-based view, which asserts that such competitive edge stems from managers' ability to identify and exploit market opportunities (see Coff, 2010). For asset-seeking firms, big data is one of the underutilised resources which can be harnessed to gain access to new knowledge, and inform and improve quality of decisions. By harnessing big data, firms would be able to unlock hidden knowledge, discover changing patterns ahead of rivals and ultimately make more informed decisions in a timely manner. Although some have postulated big data as a source of competitive advantage (McGuire, Manyika and Chui, 2012), it is contended that big data is rather a threshold resource in the new globalised environment. A key premise is that business failure could be better predicted and prevented in an era of business data.

Prior studies have emphasised the increasingly important component of BDA in organisational decision-making processes (Merendino et al., 2018; Hagel, 2015). Given that BDA is considered as "a major differentiator between high-performing and low-performing organizations" (Liu, 2014, p. 40-42), it can be argued that BDA can ultimately be utilised or to help explain why some organisations fail and others survive and enjoy continuous success in this era of big data. By becoming increasingly proactive in harnessing big data, organisations improve their strategic alertness and are able to adopt a more effective strategy in the wake of environmental shifts which threaten or weaken the capability of the firm (see Amankwah-Amoah, 2015b). By mobilising and analysing big data, firms are able to improve customers' experience and improve their overall efficiency. The issue of how organisations manage the internal resources and competences to 
deliver and sustain a competitive advantage is rooted in the resource-based theory (Barney and Clark, 2007). The arguments revolving around the ability to integrate, build and reconfigure competencies to respond to environmental shifts are anchored in the dynamic capabilities' perspective in strategic management (Teece, Pisano and Shuen, 1997). In essence, these theoretical lenses focus on accumulating, assembling and leveraging resources and capabilities to gain competitive advantage. In that sense, business failure stems from inability or failure to effectively mobilise and utilise resources and capabilities of the firm to respond to environmental threats. As such, competitive advantage in many sectors has shifted to the development and possession of scarce human capital, which underpins firms' performance. Indeed, some recent lines of research indicate that big data analytics capabilities have positive effects on supply chain agility and on achieving competitive advantage (Dubey, Gunasekaran and Childe, 2018). Thus, such key assets play a key role in determining firm survival chances in data rich settings.

A number of researchers have suggested that the ability to mobilise and utilise both structured data and unstructured data can equip firms for market competition (see Akter et al., 2016). Interestingly enough, the timely use of big data and BDA can equip firms to identify changing patterns in consumers' behaviours and their redesign or repositioning of the product or service in the light of the new information. As many firms gravitate towards innovation to catch up with market leaders, some have been forced to explore learning from failure as a means of strengthening their resilience and competitiveness. These then require organisations to proactively scan the business environment to update previously agreed decisions. There has been as growing view that learning from failure is more profitable than learning from success (Desai, 2011). The era of big data has unleashed promising opportunities for firms to harness social media data to predict the possibility of business failure. For many organisations, decisions are made in an information vacuum and as such numerous factors that could trigger and lead to business failure remain unaccounted for. Although some studies have indicated BDA as being "the next frontier 
for innovation, competition and productivity" (Manyika et al., 2011, p.1), an examination of the utilisation in determining organisational success or failure remains scarce. We seek to fill this gap in our understanding. Based on the above analysis, Figure 1 was developed which demonstrates the key components in approaches to BDAC development and understanding business failure.

\section{Figure 1: Approaches to BDAC development}

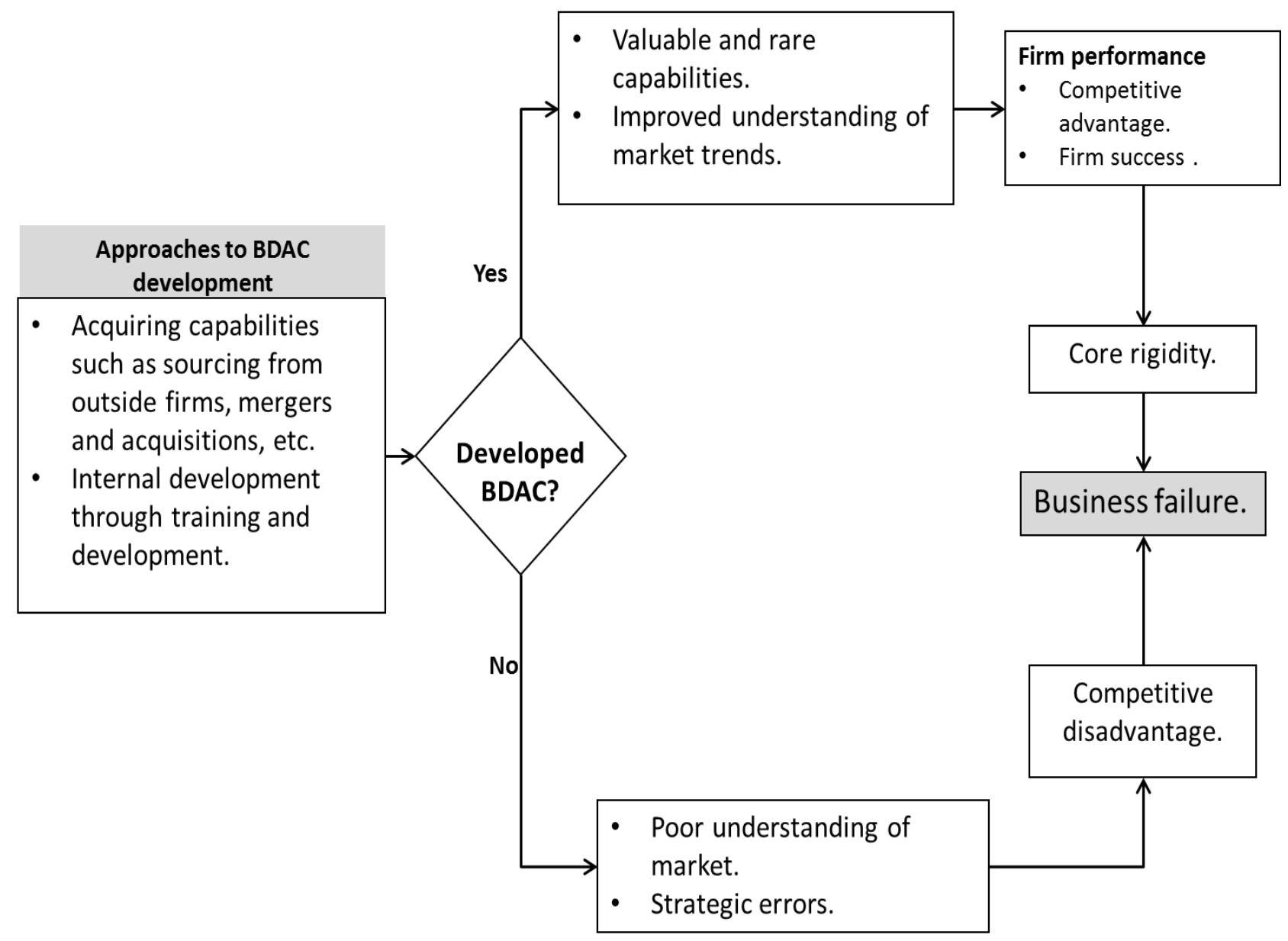

\section{Towards an integrated approach to leverage BDA to mitigate business failures}

To develop the integrated framework, it is contended that mitigating business failure using big data may stem from both the possession of distinctiveness/ordinary resources and capabilities. By threshold resources (ordinary resources), we are referring to resources required to help fulfil 
customers' requirements and prolong the firm's existence, however, the resources do not deliver competitive advantage (Grant, 2010; Johnson, Scholes and Whittington, 2009). Threshold resources/capabilities require to be "in the new game", whereas core competences/distinctiveness capabilities are firm-specific capabilities that enable firms to deliver superior performance, i.e. required to "win the game" (Grant, 2010; Johnson et al., 2009). Capabilities are anchored in firm processes, systems and routines, whereas competencies revolve around technical expertise (Daspit and D'Souza, 2017). Marcus and Anderson (2006, p. 22) put it this way, "capabilities represent the system's separate components, while competencies represent its realized wholes. Capabilities suggest potential, while competencies connote achieved proficiencies". In that sense, BDA can be viewed as a distinctive capability/core competence which is difficult to imitate or obtain, and can be utilised to underpin a firm's value-adding activities and competitive advantage (Johnson et al., 2009). Accordingly, to stay in the new competitive game, firms require big data but to outwit rivals BDA capability appears essential. In this direction, big data as an asset and BDA as a distinctive capability are central to the analysis.

Crossing these pillars produces the 2 x 2 matrix encompassing two approaches to big data as an asset (i.e. threshold resource and distinctive resource) and two types of competences in big data analytics (i.e. threshold competence and core competence), as demonstrated in Figure 2. Therefore, harnessing big data in mitigating business failure has the four dimensions. Below, we tease out the key issues and pillars of the conceptual framework. 


\section{Competences in big data analytics}
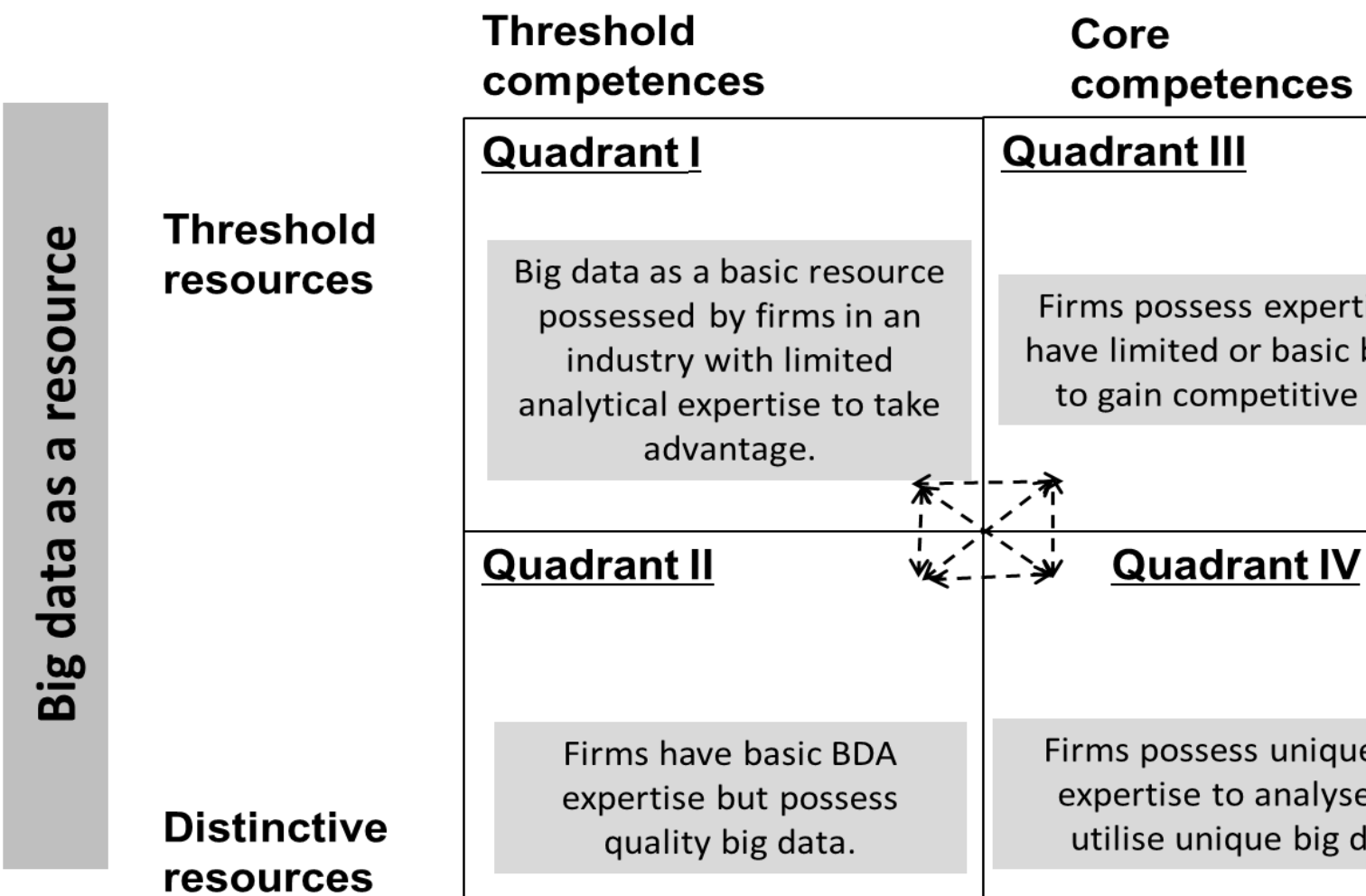

\begin{tabular}{|c|c|}
\hline $\begin{array}{c}\text { Quadrant I } \\
\text { Big data as a basic resource } \\
\text { possessed by firms in an } \\
\text { industry with limited } \\
\text { analytical expertise to take } \\
\text { advantage. }\end{array}$ & $\begin{array}{c}\text { Quadrant III } \\
\text { firms possess expertise but } \\
\text { to gain competitive edge. }\end{array}$ \\
\hline Quadrant II & $\begin{array}{c}\text { Firms possess unique BDA } \\
\text { expertise to analyse and } \\
\text { utilise unique big data. }\end{array}$ \\
\hline $\begin{array}{c}\text { Firms have basic BDA } \\
\text { expertise but possess } \\
\text { quality big data. }\end{array}$ & \\
\hline
\end{tabular}

\subsubsection{Quadrant I: Threshold resource, threshold competences}

Quadrant I is where the focal firm possesses basic big data with ordinary capabilities to harness and take advantage. The lack of highly skilled individuals in such organisations curtails its ability to assemble and utilise big data, and also leads to underestimating or overestimating of organisational problems leading to inappropriate strategic and tactical responses. Indeed, organisational leaders' limited access and ability to process quality data can inadvertently lead to misguided decisions and strategic blunders, thereby leaving the firm vulnerable to risk of business failure (Nutt, 2002). Firms in this cell may be small and medium-sized enterprises (SMEs) that typically lack BDA capability and possess basic data. In a study of failed entrepreneurs in China, Zhang (2017) found that many failed technology firms possess inferior resources and inferior data 
analytic capabilities. Such small businesses tend to possess few resources, and technical expertise to capture benefits of data analytics.

However, large businesses tend to have more financial resources to be able to upgrade their expertise and system to harness value of big data. Accordingly, they are competitively disadvantaged in the era of big data and are more likely to fail compared to larger firms in the other three quadrants. Prior research in strategy has suggested that managerial actions are often curtailed by lack of highly skilled individuals, poor visibility of organisational problems and inferior resources, which create conditions for business failure to occur (for a detailed review, see Amankwah-Amoah, 2016; Nutt, 2002). In this regard, the possession of unique BDAC provides an opportunity for firms to improve the quality of decisions. Given that data have become a strategic asset (Demirkan and Delen, 2013), the ability to utilise them would ultimately deliver some kind of competitive advantage and failure to do so is likely to lead to sub-optimal performance or even business closure. Such underutilisation of resources or limited ability to acquire scarce assets is more likely to increase the odds for business failure for firms in this quadrant. For this quadrant, the question that ought to be posed by organisational leaders is what measures have not been instituted to capture and exploit quality big data.

\subsubsection{Quadrant II: Distinctive resources, threshold competences}

Quadrant II is where the focal firm possesses unique big data but inferior expertise to harness it. Although state-owned enterprises are in decline around the globe, they often possess considerable market power and have the support of the state to collect and store data (Doganis, 2006). In spite of the expertise in assembling data, they often lack the analytical capability which hampers their competitiveness. In the new global business realities of capturing and utilising big data for market advantage, analytical capabilities have become increasingly essential ingredients for success. Rooted in BDA is the ability to mine big data to create value from the knowledge and insights. 
BDA has the potential of empowering managers with quality information upon which to act, and ensure efficient and timely deployment of scarce organisational resources. This means firms would be able to deploy resources to potential growth markets, address customers' complaints and develop products or services in tune with customers' demands. In so doing, firms would be able to improve their survival chances. To a greater extent, firms situated in this quadrant could be classified as "data wasters" (Amankwah-Amoah, 2015a). Thus, the mere possession of quality data does not deliver improved performance or competitive advantage, rather it is the ability to mobilise and apply data in a timely manner that delivers such advantage. The focal firm lacks unique expertise required to take advantage of big data and improve quality of decisions. SMEs and large firms may possess the data but often do not have the expertise to analyse and identify patterns and changes in customers' behaviour to re-align their strategy.

Firms lacking the distinctive capability are likely to falter in their attempt to retain customers due to feeble or no response to changing customers' behaviour. In today's data-rich environment, such deficiency is more likely to render such firms prime candidates for business failure. As Teece (2014) observed, such ordinary capabilities are inadequate for long-term survival of a business and therefore requires development of distinctive capabilities to improve business survival chances. Such ordinary capabilities are inadequate in delivering superior firm performance and mitigating business failure given that they can easily replicate other firms (Drnevich and Kriauciunas, 2011).

\subsubsection{Quadrant III: Threshold resources, core competences}

In recent years, a growing number of firms have explored different mechanisms in harnessing big data to improve quality of decision making (Janssen et al., 2017). Quadrant III is where the focal firm have data analytics personnel in house but possess ordinary resource, i.e. limited or basic big data, to take advantage of their expertise to gain competitive edge. Although superior human 
capital can equip firms to outwit rivals, the lack of or limited access to quality data curtails firms' ability to develop knowledge reservoirs and strategies on how firms can operate. By assembling and utilising ordinary large-scale, fast-moving and complex data, organisations are able to improve the quality of decisions but are unlikely to deliver superior advantage in the marketplace. Given that many organisations have access to the same big data, superior BDA capability is unlikely to help offset the disadvantages. The ability to use insights from ordinary data to make quality decisions is unlikely to differentiate an organisation from its rivals. However, inability to utilise the existing big data analytic capabilities such as highly skilled employees can become core rigidity. By core rigidity, we are referring to prior core competency that has shifted from an asset to become a liability due to the firm's failure to refine and upgrade in the light of changes in the business environment (Rothaermel, 2014).

\subsubsection{Quadrant IV: Distinctive resources, core competences}

Quadrant IV is where the focal firm possesses both distinctive up-to-date big data and superior BDAC. BDA also has the potential of equipping firms to reduce decision errors and create conditions to develop new sources of competitive advantage (McGuire et al., 2012). More importantly, firms in this quadrant are better positioned to navigate turbulence in the business environment such as inflation, economic decline or new taxes which might drive firms that are below industry average to extinction. Accordingly, by outperforming competitors or operating above industry average performance, firms prolong their existence (Rothaermel, 2014). The bigdata-driven decision making is more likely to create conditions for firms to take advantage of big data and deliver sustained superior performance relative to rivals.

Data-driven strategies have the potential to minimise strategic blunders and strengthen the position of firms on the leading edge of the innovations' frontier (McGuire et al., 2012). For efficiency-seeking firms, big data offers the opportunity to make decisions such as where to 
sourcing raw materials and even locate production to reduce costs. By acquiring, analysing and utilising big data, firms would be able to improve their operational capabilities and expertise. In today's data-rich world, many organisations have taken advantage of user-generated data to identify innovative ways to reduce costs, and improve efficiency and quality of services in a timely manner (Schreier and Prügl, 2008; Schreier, Fuchs and Dahl, 2012). The superior performance might stem from the elimination or reduction of decision errors and the ability to respond to market trends in a timely manner. The preceding scenario suggests that there are alternatives to decision processes and structures which can lead to failure. Having examined the characteristics of the quadrants, we now turn our attention to some of the barriers to harnessing big data to mitigate business failure.

\section{$\underline{\text { Analysis and illustrative case }}$}

The next section provides some recent examples of the key quadrants. Figure 3 provides illustration of types of organizations likely to be situated in each of the quadrants. To shed additional light on the potential effects of lack of BDAC and its effects in contributing to business failure, we turn to the recent case of the collapse European airline- Primera Air.

\section{Figure 3: Quadrant with illustrative case}




\section{Competences in big data analytics (BDA)}

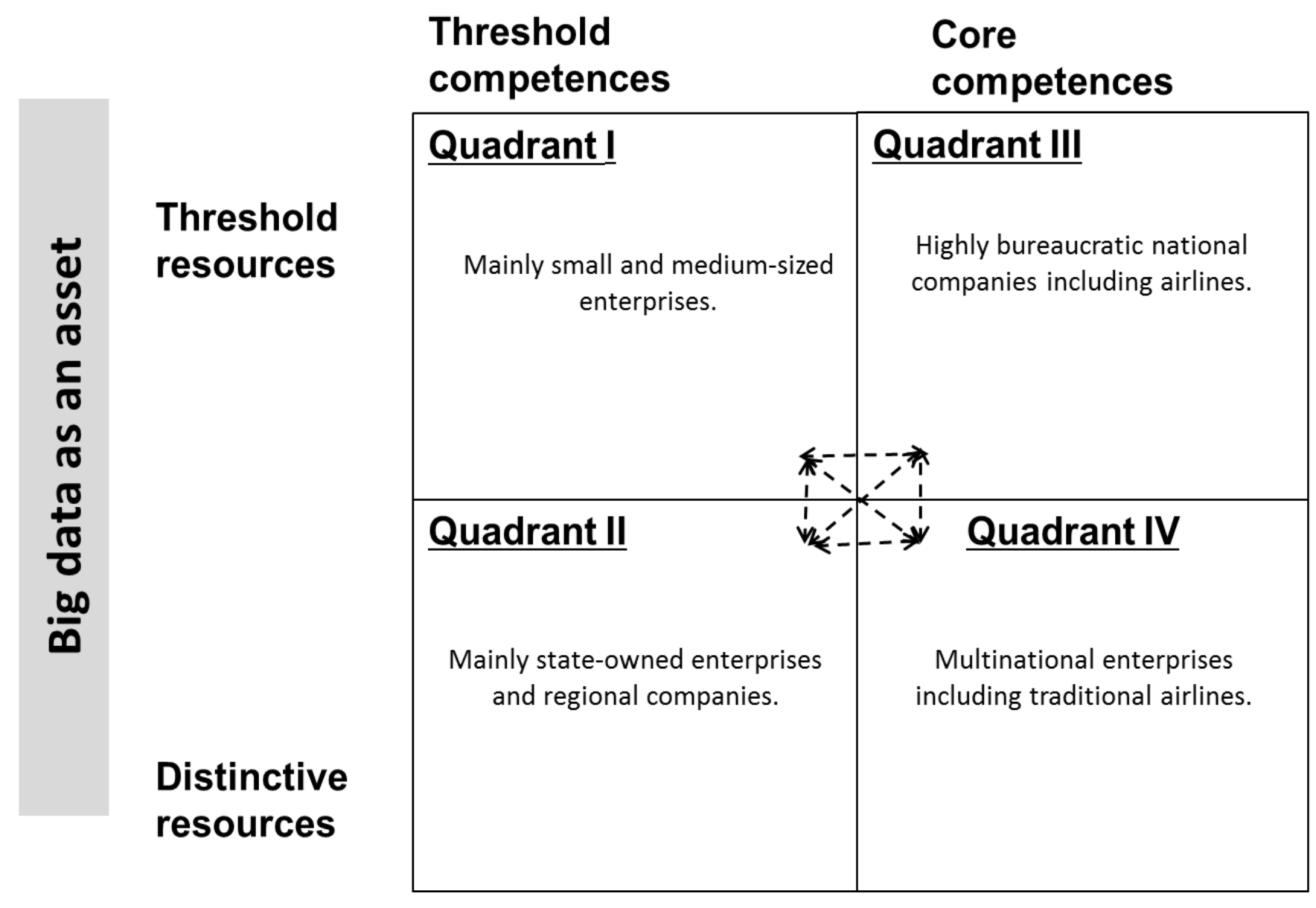

Case 1: The demise of Primera Air, 2003-2018

Primera Air was a low-cost carrier, established in 2003, and controlled by the Primera Travel Group and eventually collapsed in 2018 (Tsang, 2018). The airline was also the "launch customer for Airbus's A321LR, the longest-range version of the A321neo narrow-body jet" (Cyprus-Mail, 2018, p. nd). At its peak, it was providing both charter and scheduled services to dozens of destinations across countries in Europe, North America and the Middle East. During the 14 years 
of operations, Primera Air marketed itself as alternative to legacy and established airlines in Europe (Tsang, 2018). However, the airline terminated operations in 2018 due to a host of factors. Prominent among them was inability to capitalize on BDAC. The collapse of Primera can be attributed to failure to capitalising on data analytics. As the Financial Times noted,

"data analytics would have told the carrier it was taking a big bet on certain routes ... the most recent example of a long-haul airline start-up underestimating its need for business intelligence" (Goedeking, 2018, p.15).

Beside problems such as delayed deliveries of new aircrafts and rising fuel costs, the airline was simply operating on wrong routes due to failure to fully utilize big data analytics to inform strategic decisions. Indeed, the selected long-haul routes "raised some eyebrows" in the industry at the outset (Goedeking, 2018, p.15). Strong data analytics is imperative for start-ups seeking to outsmart incumbent airlines and selecting profitable routes. As Goedeking (2018, p.15) asserted,

"A thorough analysis of bookings, fares, flight schedules or airport passenger data would have shown Primera that its routes were extremely risky...Because getting hold of such data is very expensive, as is the ensuing analysis that can separate the routes that spell financial disaster from those that promise healthy returns. That means low-cost airlines operating long haul have a built-in bias to omit what the long-haul business relies on the use of big data to predict demand between city pairs".

Given that a very tiny proportion of today's growing unstructured data are analysed (Taylor, 2012), this opens as opportunity for airlines that develop big data analytics capabilities using social media, consumers and flights data. In today's increasingly digital economy, airlines that are able to capture and utilize social media, flight data and customers' data to inform their decisions enhance their chances of success. Given that unrivaled extensive networks of traditional airlines, lacking unique data analytics capabilities to offset the advantages inhibit small airlines' ability to 
compete. By leveraging big data, airlines are then better able to tailor their products and services to the requirements of travelers.

Compared with low-cost airlines that have thrive on short-haul routes by using secondary airports, with no or little inflight services, fewer and cheaper cabin crew, and high density seating arrangements, long haul services require airlines to develop extensive network rooted in sophisticated and predictive analytics data analysis capabilities (Doganis, 2006; Pels, 2008.; Rodríguez \& O'Connell, 2018). Following the failure to secure financial support to sustain its services, the airline eventually closed in 2018 (Kaminski-Morrow, 2018). Offering transatlantic flights for less than $£ 100$ prompted many to not only raise questions about the sustainability of the fares, but also the financial health of the whole business model (Calder, 2018).

Although the airline's board attributed the failure to "unforeseen" events (Kaminski-Morrow, 2018), much of the issues had been brewing for some time. Among the contributory factors of business failure was the loss of over $€ 10$ million incurred due to the cost of removing a fleet from service attributed to severe corrosion (Kaminski-Morrow, 2018). By faltering in harnessing live data to develop and enhance the travellers' experience through data analytics, the airline struggled to entice new customers and retain existing ones. One of the challenges faced by organizations is often lack of top talents to mobilize, code and analyze unstructured data leading to underutilized data (FT, 2012). Accordingly, only $0.5 \%$ of such potentially useful data are analyzed and utilized (FT, 2012). Goedeking (2018, p.15) puts it this way,

"It's easy to fault Primera for not using big data, but it's also not hard to understand why it didn' 't'.

In rapidly evolving global environment characterized by abundances of data, the failure of Primera Air was seen as a major setback for giants in the global aerospace industry- Airbus and Boeing given that they has utilized the carrier to "showcase for new strategies designed to use 
data analytics to help airlines run smoothly and expand their own high-margin services revenue" (Cyprus-Mail, 2018, p. nd). Besides transmission costs associated with capturing and utilizing big data in the airline industry, factors such as lack of skilled personnel and limited computational power also poses constraints (Hemmerdinger, 2018). There are also delays receiving sensor data, which affect airlines ability to capture big data (Hemmerdinger, 2018). Many of business failures today exhibit characteristics including deficiencies in big data analytics.

\section{$\underline{\text { Airlines and big data }}$}

Global competition require firms to continuously to scan the business environment and utilize big data analytics in order to stay ahead of rival firms. As Nicas (2013, p. B1) observed a few years ago, many airlines are "stuck in the 1990s when it comes to knowing their customers, saddled with older technology systems structured to keep different sets of information - loyalty programs, operations, bookings". By relying on obsolete technologies inhibit data capture for analysis, organizations are likely to sow the seed of their own demise. Given that big data is viewed as "the next frontier for innovation" (Manyika et al., 2011, p. 1; Akter, Wamba, Barrett, \& Biswas, 2018), it offers promising opportunity for innovative airlines to harness such data to help them compete.

Broadly speaking, big data analytics in quintessential in the global airline industry and many leading airline at present use big data to "pre-emptively address maintenance problems and reviewed challenges to achieving broader goals" (Hemmerdinger, 2018, p. nd). Nowadays airlines such as American, British Airways, United Continental and JetBlue have invested substantial amount into converting "disparate data into unified digital warehouses and stitching together customers' information using unique identifiers, including frequent-flier numbers, email addresses and phone numbers" (Nicas, 2013, p. B1). 
More so, United recently introduced an app that allow flight attendants to gain access to information about repeated travellers (McCartney, 2018). Allowing flight attendants to gain access to some customers' information was seen as means to improve their interaction with customers, offer personalized experiences and improve their overall improve on-board experiences (McCartney, 2018). Thus, flight attendants are able to obtain and utilise key information such as customers' seat preferences, and allergies (Nicas, 2013).

Alaska Airlines has also provided hand-held devices to its flight attendants to report harassment (McCartney, 2018). For airlines seeking growth, such capabilities are equipped them in not only planning their fleets and routes, but also enhance their capabilities to be able to perform targeted online promotions and advertising. Although "most commercial aircrafts already transmit some data directly to the ground and airlines already reap real operational benefits from data they collect", collecting and analysing "real-time sensor data and weave the findings into an active airline network - remains a prospect challenged by technology, fleet age, culture and data-access difficulties" (Hemmerdinger, 2018, p. nd).

\subsection{Barriers to harnessing big data to mitigate business failure}

Notwithstanding the potential benefits, there are factors that hinder firms in harnessing big data. First of all, it is not uncommon for organisational decision makers to ground their decisions on guesswork and intuition (Grant, 2016). Intuition as a basis for decisions may stem from personal experience and prior track record of success (Davis, 1992). Organisations with key individuals and managers who believe in "going with their gut" are unlikely to embrace the new world of big data analysis as a basis for decision making (Liebowitz, 2015). Although intuition is generally a faster approach to decision making (Simon, 1987), it has often delivered fruitless outcomes for organisational leaders compared with data-driven decisions (Grant, 2016). Given that choices and judgments of managers and leaders are often characterised by biases (Davis, 1992), decisions 
based on intuition are likely to lead to misallocation of scare resources and organisational attention. This is more so in cases of resource-poor small businesses which can lead to wrong investments. Although a number of managers believe that "intuition trumps analysis" in organisational decisions (Davenport, 2013), this line of thinking has become increasingly difficult to sustain when "there is enough data" to form the basis of informed decisions (Liebowitz, 2015). Accordingly, data analytics coupled with intuition can equip leaders in selecting the right course of action (Davenport, 2013).

A second and related barrier to harnessing big data is the issue of confirmation bias. This is where the decision maker overlooks data-driven information that contradicts their predetermined notions or strategy (Kahneman, Lovallo and Sibony, 2011). In other words, the decision makers make decisions that run counter to the evidence. By eliminating such bias in the decision-making processes, organisations are able to accrue much higher returns on their investments (Kahneman et al., 2011). For executives to acknowledge and neutralise their own bias in decision making, there is a need for different decision points and review processes that allow individuals to reflect and cool off before reaching a final decision.

In recent times, human capital has superseded physical capital in many industries including accounting, finance and software development (Groysberg, 2010). A number of studies have demonstrated that the demand for data scientists has surpassed the supply, exerting pressure on firms' ability to leverage big data for quality decisions (Lee, 2017). This has curtailed firms' ability to capture value from big data. It can be deduced that harnessing big data is partly predicated on possession of human capital. Indeed, human resource to support and inform organisational decisions is a pivotal feature in an era of big data (McAfee and Brynjolfsson, 2012). 


\section{Discussion and implications}

The paper attempted to complement prior scholarly works by examining how different access to big data and different big data analytic capabilities possessed by firms can generate different conditions leading to business failure. A key strength of this paper is the development of the fourdomain framework which captured how the different dynamics can generate different conditions leading to business failure. The framework entailed two approaches to big data as an asset (i.e. threshold resource and distinctive resource) and two types of competences in big data analytics (i.e. threshold competence/capability and core competence). The analysis pointed specifically to the increasing importance of BDA in shaping the competitiveness of firms and also the need to move beyond mere assembling big data to analytics.

One interesting observation is that ordinary big data analytic capabilities and mere possession of big data are more likely to create conditions for business failure. On the basis of the above analysis, the failure by some firms to transition from intuition-based decision making to a purely big-data-driven decision-making approach may explain why some firms fail whilst others see their competitive advantage erode. This is also consistent with the notion that BDA is an indispensable element in today's hyper competitive business environment (Akter et al., 2016, 2018; Gupta and George, 2016).

Taken together, the analysis demonstrated that the mere possession of or access to big data is unlikely to yield success or competitive advantage, rather it is the ability to mine and utilise big data that can better equip firms to mitigate business failure and improve their competitiveness. This finding is consistent with well-established theoretical arguments in strategy that the mere possession of an asset is unlikely to yield competitive advantage but rather the ability to utilise the assets (Teece et al., 1997). 


\subsection{Contributions to theory and practice}

Regarding theoretical implications, our framework contributes to big data and big data analytics (Akter et al., 2016, 2018; Wamba et al., 2017) and business failure research (Amankwah-Amoah, 2016; Zhang et al., 2018) by deepening our understanding of the relationship between these two important subjects. The study also advances the literatures by clarifying how lack of data analytic capabilities could lead to business failure in some industries. In addition, given that both empirical and conceptual papers are essential for fields of study to flourish, it is surprising that the number of conceptual papers is in sharp decline (Yadav, 2010). The dearth of conceptual articles has in many ways limited theoretical development and advancements. In this direction, this study also responds to the call for new streams of conceptual papers as a means of revitalising social science subjects and expanding the body of knowledge (Yadav, 2010).

The preceding analysis offers some practical implications. First, the analysis highlights that the era of big data requires strategic agility, where firms continuously scan the business environment to update their knowledge and adjust their strategy as new sets of data and information emerge (Doz and Kosonen, 2010; Dubey et al., 2018). Although achieving such strategic agility can be costly (Doz and Kosonen, 2010; Teece, Peteraf and Leih, 2016), it represents overall long-term efficient utilisation of resources given the savings from strategic blunders, errors, and misallocation of resources and organisational attention. Cultivating BDAC requires crossfunctional teams within the organisation to translate big data into actionable knowledge for activities with the firm.

In the atmosphere of increasing reluctance to embrace BDA, mobilising organisational support and evidence would be the most effective driver for more data-driven decisions. To overcome big data analytic capability deficiency, organisations can focus on human capital development through training and workshops to raise awareness of big data utilisation and benefits to help 
overcome some of the cultural barriers. To surmount some of the challenges around skills formation, firm-specific training might be needed given the divergent approaches to data analysis.

Over the course of this century, analytics might shift from a distinctive competence/capability to become a threshold competence given the improvements in modern data-science technologies. Besides accumulating a superior big data, firms also need to match this with superior analytic capability to outwit rivals. Enhancing the data analytical capabilities is seen as essential in instilling problem-solving and evidence-based culture in organizations.

\subsection{Limitations and directions for further research}

Along with the key strengths of the paper are some limitations. The first relates to the assumption that business failure is "bad". There is an accumulated body of research that demonstrates that failure has positive externalities (Knott and Posen, 2005). Besides freeing up resources and knowledge for surviving firms to tap, business failure offers an opportunity to learn from other firms (Knott and Posen, 2005). Another limitation has to do with the exclusive focus on using big data to identify early signals of underperformance and business failure. This fails to capture informal or unreported or underreported actions and behaviours which can also create conditions for business failure to occur. In addition, it is conceivable that this conceptualisation overlooks some aspects of big data and the complexity of the subject.

Nevertheless, it offers a useful starting point towards integrating resources and capabilities in harnessing big data. Notwithstanding the limitations, there are promising lines for future research. First, an interesting question for future research relating to Quadrant IV is how can firms so efficient in utilising big data renew themselves and not become complacent, thus leading to failure? Related to Quadrant I is a question of how firms enjoying sub-optimal performance can apply big data to leapfrog rivals and transition into Quadrant IV. It might also be worthwhile for 
future studies to explore how third-party organisations utilise BDA in advising and soliciting clients. The analysis also highlights the need for a more detailed analysis of how failure can be predicted using big data.Finally, it is hoped that this piece helps to stimulate new streams of research on big data and business failure.

\section{References}

Adeleye, I., Amankwah-Amoah, J., Boso, N., \& Esposito, M. (2017). Africa's competitiveness in the global economy: Past, present and future. I. Adeleye \& M. Esposito (Eds.). Africa's Competitiveness in the Global Economy. Basingstoke: Palgrave.

Akter, S., Wamba, S. W., Barrett, M., \& Biswas, K. (2018). How talent capability can shape service analytics capability in the big data environment? Journal of Strategic Marketing, 1-19.

Akter, S., Wamba, S.F., Gunasekaran, A., Dubey, R., Childe, S.J. (2016). How to improve firm performance using big data analytics capability and business strategy alignment? International Journal of Production Economics, 182, 113-131.

Amankwah-Amoah, J. (2015a). Safety or no safety in numbers? Governments, big data and public policy formulation. Industrial Management and Data System, 115(9), 1596-1603.

Amankwah-Amoah, J. (2015b). A unified framework for incorporating decision-making into explanations of business failure. Industrial Management and Data System, 115(7), 1341-1357.

Amankwah-Amoah, J. (2016). An integrative process model of organisational failure. Journal of Business Research, 69(9), 3388-3397.

Amankwah-Amoah, J. (2018). Human Capital Flows in Failing Organizations: An Integrated Conceptual Framework. Journal of Intellectual Capital, 19(4), 732-746.

Amankwah-Amoah, J., Antwi-Agyei, I., \& Zhang, H. (2018). Integrating the dark side of competition into explanations of business failures: Evidence from a developing economy. European Management Review, 15(1), 97-109.

Amankwah-Amoah, J., Boso, N., \& Antwi-Agyei, I. (2016). The effects of business failure experience on successive entrepreneurial engagements: An evolutionary phase model. Group \& Organization Management, 1059601116643447.

Barney, J.B., \& Clark, D.N. (2007). Resource-based Theory: Creating and Sustaining Competitive Advantage. Oxford University Press, Oxford.

Bartels, B., Ermel, U., Sandborn, P., \& Pecht, M.G. (2012). Strategies to the Prediction, Mitigation and Management of Product Obsolescence. John Wiley \& Sons, Hoboken, New Jersey.

Baumard, P., \& Starbuck, W. H. (2005). Learning from failures: why it may not happen. Long Range Planning, 38, 281-298. 
Bharadwaj, N., \& Noble, C. H. (2015. Innovation in data-rich environments. Journal of Product Innovation Management, 32, 476-78.

Brown, M. S. (2016). How to avoid data analytics failure. Feb 28, 2016. https://www.forbes.com/sites/metabrown/2016/02/28/how-to-avoid-data-analyticsfailure/\#769c379a3155.

Byrne, O., \& Shepherd, D. A. (2015). Different strokes for different folks: Entrepreneurial narratives of emotion, cognition, and making sense of business failure. Entrepreneurship Theory and Practice, $39(2), 375-405$.

Caesarius, L. M., \& Hohenthal, J. (2018). Searching for big data: How incumbents explore a possible adoption of big data technologies. Scandinavian Journal of Management, 34, 129-140.

Calabretta, G., Gemser, G., \& Wijnberg, N. M. (2017). The interplay between intuition and rationality in strategic decision making: A paradox perspective. Organization Studies, 38(3/4), 365-401.

Calder, S. (2018). Primera Air Collapse: Why Wasn't The Public Warned About The Airline Going Bust? https://www.independent.co.uk/travel/news-and-advice/primera-air-airline-budget-collapsefailure-passengers-stranded-a8569066.html.

Cobb, A. N., Benjamin, A. J., Huang, E. S., \& Kuo, P. C. (2018). Big data: More than big data sets. Surgery, 164, 640-642.

Coff, R. W. (2010). The coevolution of rent appropriation and capability development. Strategic Management Journal, 31, 711-733.

Curren, M. T., Folkes, V. S., \& Steckel, J. H. (1992). 'Explanations for successful and unsuccessful marketing decisions: The decision maker's perspective. Journal of Marketing, 56, 18-31.

Cyprus-Mail (2018). Budget airline Primera Air ceases operations. https://cyprusmail.com/2018/10/02/budget-airline-primera-air-ceases-operations/.

Daspit, J. J., \& D'Souza, D. E. (2017). Capability configuration in software industry SMEs: The CAO model of ordinary capabilities. Journal of Small Business Management. 55, 141-162.

D'Aveni, R. A. (1989a). The aftermath of organizational decline: A longitudinal study of the strategic and managerial characteristics of declining firms. Academy of Management Journal, 32, 577-605.

D'Aveni, R. A. (1989b). Dependability and organizational bankruptcy: An application of agency and prospect theory. Management Science, 35, 1120-1138.

Davenport, T. H. (2013). Big data and the role of intuition. Harvard Business Review. 12/24/, 2-3.

Davis, J. H. (1992). Some compelling intuitions about group consensus decisions, theoretical and empirical research, and interpersonal aggregation phenomena: Selected examples, 1950-1990. Organizational Behavior and Human Decision Processes, 52, 3-38.

Demirkan, H., \& Delen, D. (2013). Leveraging the capabilities of service-oriented decision support systems: Putting analytics and big data in cloud. Decision Support Systems, 55(1), 412-421.

Desai, V. (2011). Mass media and massive failures: determining organizational efforts to defend the field's legitimacy following crises. Academy of Management Journal, 54, 263-278. 
Doganis, R. (2006). The airline business (2nd ed.). London: Routledge.

Doz, Y., \& Kosonen, M. (2010). Embedding strategic agility: A leadership agenda for accelerating business model renewal. Long Range Planning, 43(2): 370-382.

Drnevich, P. L., \& Kriauciunas, A. P. (2011). Clarifying the conditions and limits of the contributions of ordinary and dynamic capabilities to relative firm performance. Strategic Management Journal, 32(3), 254-279.

Dubey, R., Gunasekaran, A., \& Childe, S. J. (2018). Big data analytics capability in supply chain agility: The moderating effect of organizational flexibility. Management Decision.

Dunn, G. (2018). Analysis: How Air Berlin capacity has been replaced. 23 August. https://www.flightglobal.com/news/articles/analysis-how-air-berlin-capacity-has-been-replaced$451298 /$.

Fan, S., Lau, R. Y., \& Zhao, J. L. (2015). Demystifying big data analytics for business intelligence through the lens of marketing mix. Big Data Research, 2(1), 28-32.

Francis, G., Dennis, N., Ison, S., \& Humphreys, I. (2007). The transferability of the low-cost model to long-haul airline operations. Tourism management, 28(2), 391-398.

FT (2012). Lack of data analysis worrisome. https://www.ft.com/content/67d7de00-43d3-11e2-844c$\underline{00144 f e a b d c 0}$.

Goedeking, P. (2018). Collapse of Primera shows the risks of low-cost long haul. Financial Times, Oct 4, 15.

Grant, A. M. (2016). Originals: How non-conformists move the world. New York: Viking.

Grant, R. M. (2010). Contemporary strategy analysis. 7th Ed. Chichester: Wiley.

Groysberg, B. (2010). Chasing Stars: The Myth of Talent and the Portability of Performance, Princeton, NJ: Princeton University Press.

Gupta, M., \& George, J. F. (2016). Toward the development of a big data analytics capability. Information \& Management, 53(8), 1049-1064.

Hagel, J. (2015). Bringing analytics to life. Journal of Accountancy, 219, 24-25.

Hemmerdinger, J. (2018). Analysis: Why fuller 'big data' benefits remain unrealized. 10 September https://www.flightglobal.com/news/articles/analysis-why-fuller-big-data-benefits-remain-unre$451764 /$.

Hessels, J., Grilo, I., Thurik, R., \& van der Zwan, P. (2011). Entrepreneurial exit and entrepreneurial engagement. Journal of Evolutionary Economics, 21, 447-471.

Horita, F. E., de Albuquerque, J. P., Marchezini, V., \& Mendiondo, E. M. (2017). Bridging the gap between decision-making and emerging big data sources: an application of a model-based framework to disaster management in Brazil. Decision Support Systems, 97, 12-22.

Janssen, M., van der Voort, H., \& Wahyudi, A. (2017). Factors influencing big data decision-making quality. Journal of Business Research, 70, 338-345. 
Jarrell, J. (2018).The future of digital technology in the aviation industry. 2 October. https://www.internationalairportreview.com/article/76057/future-digital-technology/.

Jiang, H., Cannella, A. A, Xia, J., \&. Semadeni, M. (2017). Choose to fight or choose to flee? A network embeddedness perspective of executive ship jumping in declining firms. Strategic Management Journal. DOI: 10.1002/smj.2637.

Johnson, G., Scholes, K., \& Whittington, R. (2009). Fundamentals of strategy. Harlow: Pearson Education Limited.

Kahneman, D., Lovallo, D. \& Sibony, O. (2011). Before you make that big decision, Harvard Business Review, 89(6) 50-60.

Kaisler, S., Armour, F., Espinosa, J. A., \& Money, W. (2013). Big data: Issues and challenges moving forward. In System sciences (HICSS), 2013 46th Hawaii international conference on (pp. 9951004). IEEE.

Kaminski-Morrow, D. (2018). Struggling Primera Air to cease operations. 01 OCTOBER. https://www.flightglobal.com/news/articles/struggling-primera-air-to-cease-operations-452337/.

Knott, A. M., \& Posen, H. E. (2005). Is failure good? Strategic Management Journal, 26, 617-641.

LaValle, S., Lesser, E., Shockley, R., Hopkins, M. S., \& Kruschwitz, N. (2011). Big data, analytics and the path from insights to value. MIT Sloan Management Review, 52(2), 21.

Lee, I. (2017). Big data: Dimensions, evolution, impacts, and challenges. Business Horizons, 60, 293-303

Leeflang, P. S., Verhoef, P. C., Dahlström, P., \& Freundt, T. (2014). Challenges and solutions for marketing in a digital era. European Management Journal, 32(1), 1-12.

Liebowitz, J. (2015). Intuition-based decision-making: The other side of analytics. March/April 2015, http://analytics-magazine.org/forum-intuition-based-decision-making-the-other-side-of-analytics/.

Liu, Y. (2014). Big data and predictive business analytics. Journal of Business Forecasting, 33, 40-42.

Manyika, J., Chui, M., Brown, B., Bughin, J., Dobbs, R., Roxburgh, C., \& Byers, A. H. (2011). Big data: the next frontier for innovation, competition and productivity. McKinsey Global Institute.

Marcus, A. A., \& Anderson, M. H. (2006). A general dynamic capability: does it propagate business and social competencies in the retail food industry? Journal of Management Studies, 43(1), 19-46.

Marks, M. L., \& Vansteenkiste, R. (2008). Preparing for organizational death: Proactive HR engagement in an organizational transition. Human Resource Management, 47(4), 809-827.

Maugis, P.-A. G. (2018). Big data uncertainties. Journal of Forensic and Legal Medicine 57, 7-11.

Mcafee, A., \& Brynjolfsson, E. (2012). Big data: The management revolution. Harvard Business Review, 60(68), 128.

McCartney, S. (2018). What the Airline Knows About the Guy in Seat 14C. Wall Street Journal (Online), 20 June: $\mathrm{n} / \mathrm{a}$. 
McGuire, T., Manyika, J., \& Chui, M. (2012). Why big data is the new competitive advantage. Ivey Business Journal, 76(4), 1-4.

Mellahi, K., \& Wilkinson, A. (2004). Organizational failure: A critique of recent research and a proposed integrative framework. International Journal of Management Reviews, 5, 21-41.

Merendino, A., Dibb, S., Meadows, M., Quinn, L., Wilson, D., Simkin, L., \& Canhoto, A. (2018). Big data, big decisions: The impact of big data on board level decision-making. Journal of Business Research, 93, 67-78.

Nicas, J. (2013). How airlines are mining personal data in-flight. Wall Street Journal, 08 Nov, B.1.

Nikolopoulos, K., \& Petropoulos, F. (2018). Forecasting for big data: Does suboptimality matter? Computers \& Operations Research, 98, 322-329.

Nutt, P. C. (2002). Why decisions fail: Avoiding the blunders and traps that lead to debacles. San Francisco, C.A.: Berrett-Koehler.

Pels, E. (2008). Airline network competition: Full-service airlines, low-cost airlines and long-haul markets. Research in transportation economics, 24(1), 68-74.

Perrons, R. K., \& Jensen, J. W. (2015). Data as an asset: What the oil and gas sector can learn from other industries about "big data". Energy Policy, 81, 117-121.

Rodríguez, A. M., \& O’Connell, J. F. (2018). Can low-cost long-haul carriers replace Charter airlines in the long-haul market? A European perspective. Tourism Economics, 24(1), 64-78.

Ronstadt, R. (1986). Exit, stage left: Why entrepreneurs end their entrepreneurial careers before retirement. Journal of Business Venturing, 1(3), 323-338.

Rothaermel, F. T. (2014). Strategic management (2nd ed.). Burr Ridge, IL: McGraw-Hill.

Schreier, M., \& Prügl, R. (2008). Extending lead-user theory: Antecedents and consequences of consumers' lead userness. Journal of Product Innovation Management, 25(4, 331-346.

Schreier, M., Fuchs, C., \& Dahl, D.W. (2012). The innovation effect of user design: Exploring consumers' innovation perceptions of firms selling products designed by users. Journal of Marketing, 76(5), 18-32.

Schumpeter, J. A. (1964). Business cycles: A theoretical, historical, and statistical analysis of the capitalist process. Porcupine Press: Philadelphia.

Semadeni, M., Cannella, A. A., Fraser, D. R., \& Lee, D. S. (2008). Fight or flight: Managing stigma in executive careers. Strategic Management Journal, 29, 557-567.

Sheng, J., Amankwah-Amoah, J., \& Wang, X. (2017). A multidisciplinary perspective of big data in management research. International Journal of Production Economics, 191, 97-112

Silverman, B. S., Nickerson, J. A., \& Freeman, J. (1997). Profitability, transactional alignment, and organizational mortality in the US trucking industry. Strategic Management Journal, 31-52.

Simon, H. A. (1987). Making management decisions: The role of intuition and emotion. Academy of Management Executive, 1, 57-64. 
Taylor, P. (2012). Lack of data analysis worrisome. Financial Times, https://www.ft.com/content/67d7de00-43d3-11e2-844c-00144feabdc0.

Teece, D. J. (2014). A dynamic capabilities-based entrepreneurial theory of the multinational enterprise. Journal of International Business Studies, 45(1), 8-37.

Teece, D. J., Pisano, G., \& Shuen, A. (1997). Dynamic capabilities and strategic management. Strategic Management Journal, 18(7), 509-533.

Teece, D., Peteraf, M., \& Leih, S. (2016). Dynamic capabilities and organizational agility. California Management Review, 58(4), 13-35.

Tsang, A. (2018).Passengers are stranded as another European airline collapses. https://www.nytimes.com/2018/10/02/business/primera-air-collapse.html.

Wamba, S. F., Akter, S., \& De Bourmont, M. (2018). Quality dominant logic in big data analytics and firm performance. Business Process Management Journal.

Wamba, S. F., Akter, S., Trinchera, L., \& De Bourmont, M. (2018). Turning information quality into firm performance in the big data economy. Management Decision.

Wamba, S. F., Gunasekaran, A., Akter, S., Ren, S. J. F., Dubey, R., \& Childe, S. J. (2017). Big data analytics and firm performance: Effects of dynamic capabilities. Journal of Business Research, 70, 356-365.

Wamba, S. F., Gunasekaran, A., Dubey, R., \& Ngai, E. W. (2018). Big data analytics in operations and supply chain management. Annals of Operations Research, 270(1-2), 1-4.

Wamba, S.F., Akter, S., Edwards, A., Chopin, G., \& Gnanzou, D. (2015). How 'big data' can make big impact: Findings from a systematic review and a longitudinal case study. International Journal of Production Economics, 165, 234-246.

Wiesenfeld, B. M., Wurthmann, K. A., \& Hambrick, D. C. (2008). The stigmatization and devaluation of elites associated with corporate failure: a process model. Academy of Management Review, 33, 231-251.

Xiong, G., \& Bharadwaj, S. (2013). Asymmetric roles of advertising and marketing capability in financial returns to news: Turning bad into good and good into great. Journal of Marketing Research, 50(6), 706-724.

Yadav, M. (2010). The decline of conceptual articles and implications for knowledge development. Journal of Marketing, 74(1), 1-19.

Zhang H. (2017). Small businesses failure in emerging economies: Insights from failed Chinese entrepreneurs. Bristol: University of Bristol.

Zhang, H., Amankwah-Amoah, J., \& Beaverstock, J. (2018). Toward a construct of dynamic capabilities malfunction: Insights from failed Chinese entrepreneurs. Journal of Business Research. 